\title{
Three-year performance of a nano-filled resin-modified glass ionomer cement in class II primary molar restorations
}

\author{
Dermata, A ; Papageorgiou, S N ; Kotsanos, N
}

\begin{abstract}
PURPOSE To compare the clinical failure rate of two resin-modified glass ionomer cements (RMGICs) used for Class II primary molar restorations over a 3-year period. METHODS Healthy, cooperative children aged 4-8 years with carious, asymptomatic primary molars requiring class II restorations received either nanofilled (Ketac Nano, 3 M ESPE) or regular (Vitremer, 3 M ESPE) RMGIC restorations. These were blindly assessed semiannually for 3 years using the modified USPHS criteria with all-cause failure as primary outcome and failure for each criterion as secondary outcome. Data was analysed with Fisher's exact tests and survival analysis with robust standard errors at 5\%. RESULTS Outcome assessment included 159 teeth at 12 months, 141 teeth at 24 months, and 98 teeth at 36 months. No difference in all-cause failure was found between regular and nano-filled RMGIC at 12 (8.6\% versus $14.1 \%), 24(9.0 \%$ versus $14.9 \%)$ or 36 months $(7.4 \%$ versus $20.5 \%)(\mathrm{P}>0.05)$. The nanofilled RMGIC retained better its anatomical form and the regular RMGIC likewise its marginal integrity $(\mathrm{P}<0.05)$, but only in the acceptable range (Alpha-Bravo). Overall, survival analysis found no significant difference for allcause failure [hazard ratio (HR) 0.58 ; $95 \%$ confidence interval (CI) $0.25-1.31 ; \mathrm{P}=0.19$ ] or any secondary outcomes other than contact point integrity. Finally, subgroup analysis by jaw indicated that the regular RMGIC performed better than the nano-filled RMGIC for mandibular molars (HR 0.36; 95\% CI 0.13-0.96; P = 0.04), but further data are needed. CONCLUSION Nano-filled RMGIC showed less occlusal wear but more mild marginal defects than regular RMGIC, but these findings were of limited clinical significance and both materials performed favourably for 3 years.
\end{abstract}

DOI: https://doi.org/10.1007/s40368-020-00574-2

Posted at the Zurich Open Repository and Archive, University of Zurich

ZORA URL: https://doi.org/10.5167/uzh-194585

Journal Article

Accepted Version

Originally published at:

Dermata, A; Papageorgiou, S N; Kotsanos, N (2021). Three-year performance of a nano-filled resin-modified glass ionomer cement in class II primary molar restorations. European Archives of Paediatric Dentistry, 22(3):425-432. DOI: https://doi.org/10.1007/s40368-020-00574-2 


\title{
Three year performance of a nanofilled resin modified glass ionomer in class II primary molar restorations.
}

\author{
A. Dermata ${ }^{1} \cdot$ S.N. Papageorgiou ${ }^{2} \cdot$ N. Kotsanos ${ }^{1}$ \\ 1 Department of Paediatric Dentistry, Dental School, Aristotle University of Thessaloniki \\ ${ }^{2}$ Clinic of Orthodontics and Pediatric Dentistry, Center of Dental Medicine, University of Zurich \\ Corresponding author: Anastasia Dermata; dermatasa@gmail.com.
}

Words in abstract:239

Words in text: 2700

Corresponding Author: Anastasia Dermata, DDS, Msc, Aristotle University of Thessaloniki GREECE Corresponding Author Secondary

Information:

Corresponding Author's Institution: Aristotle University of Thessaloniki

Corresponding Author's Secondary Institution:

First Author: Anastasia Dermata, DDS, Msc, Aristotle University of Thessaloniki, Greece

First Author Secondary Information:

Order of Authors: Anastasia Dermata, DDS, Msc

Spyridon N. Papageorgiou, DDS, Dr med dent

Nikolaos Kotsanos, DDS, Msc, Phd, Professor

Ethics approval: Approval for this study was acquired from the Dental Faculty Ethics Committee (186/10-52012).

Consent: The legal guardians of all patients provided written informed consent before participating in this trial.

Data availability: All data are openly provided without restrictions through Zenodo (DOI:10.5281/zenodo.3786162).

Authors' contributions: AD assorted and tabulated data and wrote the first draft of the manuscript.

SNP blindly performed data analyses and revised the manuscript. NK conceived the project idea, designed and executed restorative part of the trial, and revised the manuscript. 


\section{Abstract}

Aim: To compare the clinical failure rate of two Resin Modified Glass lonomer Cements (RMGICs) used for Class II primary molar restorations over a 3-year period.

Methods: Healthy, cooperative children aged 4-8 years with carious, asymptomatic primary molars requiring class II restorations received either nano filled (Ketac Nano, 3M ESPE) or regular (Vitremer, 3M ESPE) RMGIC restorations. These were blindly assessed semi-annually for three years using the modified USPHS criteria with all-cause failure as primary outcome and failure for each criterion as secondary outcome. Data was analysed statistically with Fisher's exact tests and survival analysis with robust standard errors at $5 \%$.

Results: Results: Outcome assessment included 159 teeth at 12 months, 141 teeth at 24 months, and 98 teeth at 36 months. No statistically significant difference in all-cause failure was found between Vitremer and Ketac Nano at 12 months (8.6\% versus $14.1 \%), 24$ months (9.0\% versus $14.9 \%)$ or 36 months $(7.4 \%$ versus $20.5 \%)(p>0.05)$. The nano filled retained better its anatomical form and the regular RMGIC likewise its marginal integrity $(p<0.05)$, but only in the acceptable range (Alpha-Bravo). Overall, survival analysis found no significant difference for all-cause failure (Hazard Ratio $[H R]=0.58 ; 95 \%$ Confidence Interval $[\mathrm{Cl}]=0.25-1.31 ; \mathrm{p}=0.19)$ or any secondary outcomes.

Conclusion: The nano filled primary molar class II restorations showed less occlusal wear but more mild marginal defects than those with the regular RMGIC. These findings were of limited clinical significance and both materials performed favourably for 3 years. 


\section{Introduction}

The demand for aesthetic and minimally invasive restorations [Hickel 1996] as well as the concerns about the toxicity of amalgam to patients and the ecosystem [Eley1997] has led to an increased use of other toothcoloured dental restorative materials. For primary molars in particular, composite resin, glass ionomer cements and their combinations or modifications are being primarily used, and the choice among them remains a challenge for the clinician, as factors like operator friendliness, cavity size, proximity to the pulp, working field control and possibly others have to be considered. Despite superior mechanical properties and aesthetics, composite resin is a material that requires a strict placement protocol, and its successful placement can be jeopardized when satisfactory tooth isolation or patient cooperation cannot be achieved. The polymerization shrinkage of resin is a feature associated with long term failure of composite restorations causing sensitivity, marginal leakage and discolouration, loss of retention and secondary caries.

Glass ionomer cements (GIC) have been used as restorative material in dentistry since the early 1970s. Their advantages, such as chemical bonding to enamel and dentin, biocompatibility, release (and uptake) of fluoride, thermal expansion resembling that of the tooth and decreased moisture sensitivity compared to resin composites, made them attractive for use in children. Frequency of fractured restorations soon revealed clinically their low compressive and flexural strength. This was overcome by introducing the resin modified glass ionomer cements (RMGIC), which are shown to be a suitable class II restorative material for primary molars [Chadwick and Evans, 2007]. RMGICs are still based in the acid-base reaction to retain the GIC advantages. The addition of resin not only allowed a fast initial form taking by light polymerization but made the material more durable by significantly improving its mechanical properties. A recent study showed no difference at two-year survival rates between RMGIC and composite [Dermata et al, 2018], while Kotsanos and Arizos [2011] remains the only study to have shown successful 2.5 year RMGIC survival of oversized class II restorations of deeply carious primary molars. A finding in this last study was that there was increased, still clinically acceptable, occlusal wear of the RMGIC restoration material.

The introduction of nano sized inorganic particles in both resin composite and RMGIC restorative materials occurred in the first decade of the current century [Killian and Croll, 2010]. Nano filled materials allowed for increased polishability and this improved surface reflection and aesthetics, while this technology 
was considered important for the superior resistance to biomechanical degradation [de Paula et al, 2011]. Additionally, the nano filled RMGIC product Ketac Nano is being advertised as having improved wear resistance (3M Ketac data files). However, Abo-Hamar et al [2015] in one of the very few independent clinical studies reported notable wear, marginal discoloration and secondary caries (8\%), all being not statistically different to those of regular RMGIC. Another study found no statistically significant difference between this nano filled and another regular RMGIC with respect to anatomical form after 1 year, when the two materials were placed as ART in proximo-occlusal cavities [Konde et al, 2012].

The aim of the present study was to compare clinical success parameters of two RMGICs used in children for Class II primary molar restoration over a 3-year period. The hypothesis was that there was no difference between the nano filled and the regular RMGIC.

\section{Materials and methods}

The clinical part of the study was conducted prospectively at the part-time private specialty evening clinic of a University employed pediatric dentist. The study was a practice/University joint project. It was planned, and its results statistically analyzed at Aristotle University and it was institutionally approved by its Dental Faculty Ethics Committee (186/10-5-2012). Healthy (ASA I, II) and co-operative (FrankI 3,4) 4- to 8-yearold children, regular patients of the clinic, with vital primary molars requiring class II restoration in their carious cavities were eligible to enter the study. Diagnostic radiographs were always taken. Exclusion criteria were dentin caries radiolucency in close proximity to the pulp feared for possible pulp exposure, clinical signs or symptoms of pulp involvement, i.e. pain history, and cavities related to preexisting developmental defects, e.g. primary molar hypomineralisation (similar to molar incisor hypomineralisation, $\mathrm{MIH})$. Parents were informed that both restorative materials to be used were recommended for this type of cavity and, if they consented, the child entered the study. Ketac Nano and Vitremer (both kindly provided by $3 \mathrm{M}$ ESPE) were used during a nine-month restoration placement period, with the material used in each month being randomly chosen by tossing a coin.

\section{Restorative technique}


All restorations were placed under local anaesthesia and rubber-dam isolation by a single experienced paediatric dentist (NK) who kept coded records of children and restorations. Cavities were cut with a small cylindrical high-speed diamond bur, while soft carious dentin was removed with a small hand excavator followed by a No. 4 or 5 round, low-speed steel bur. The latter secured that there was only hard dentin at the cavity and especially at the box peripheral walls for adequate bonding with either material. A piece of $5 \mathrm{~mm}$ width thin steel matrix band was secured around the proximal surface with a wooden wedge suitable for primary molars. Both materials, Vitremer and Ketac Nano were placed according to the manufacturer's instructions. For Ketac Nano an A2 shade was used to match the light Vitremer shade selected.

For the regular RMGIC restorations, the primer was applied for 30 seconds, blown gently and light cured for 10 seconds. The powder and liquid doses were manually mixed, placed in the cavity through the recommended applicator's tip, lightly condensed and excess material was curved with hand instruments. The restoration was light-cured for 40 seconds. Trimming and polishing of the restoration was performed with a conical Arkansas stone. The Vitremer finishing gloss was applied using a microbrush, gently blown and light cured for 20 seconds. After the removal of the rubber-dam, the occlusal surface was checked for need of additional trimming.

For the nano filled RMGIC restorations, the primer was applied in a similar manner. The Ketac Nano two-paste dose was dispensed by the $3 \mathrm{M}^{\mathrm{TM}}$ Clicker $^{\mathrm{TM}}$ dispenser mixed and placed in the cavity through the recommended applicator's tip (same as with Vitremer). The rest was identical with the Vitremer procedure except that, according to the manufacturer, there was no need for finishing gloss coating.

\section{Assessment of restorations}

The restorations were assessed clinically at baseline and semiannually. For the evaluation of the restorations a modification of the United States Public Health Service criteria was used, as in Kotsanos and Arizos [2011]. The marginal integrity, the proximal contact, the anatomical form, the surface texture and the presence of secondary caries were individually judged as A (Alpha), B (Bravo) (except for caries), C (Charlie) or D (Delta) (except for caries), as seen in table 1. Restorations rated as A or B were judged as acceptable, while those rated as $\mathrm{C}$ or $\mathrm{D}$ were judged as unacceptable. For reasons explained in Kotsanos and Arizos [2011] and related to teeth being often mobile to various extend when closer to exfoliation at late 
follow-ups, and therefore with added confounders, the contact point parameter was considered unsuitable for long term studies with primary molars. Assessment was done in a blind manner by the same author (NK) and recorded by his assistant at patient follow-up evaluations. Blindness was possible due to matching shades of the two materials.

\section{Data Analysis}

Descriptive statistics were calculated, consisting of absolute/relative frequencies and means with Standard Deviations (SD) or medians with Interquartile Ranges (IQR) according to normality check. Initial crude differences between groups were assessed with Fisher's exact test. Additionally, survival analysis was employed to assess all-cause failure, while accounting for the variable follow-up of each patient. After checking assumptions, log-rank tests were used to find differences between groups. The failure risk at each time-point was initially assessed with Cox shared frailty regression models. Each confounder was inserted in a separate bivariable model for each outcome and confounders with $\mathrm{P} \leq 0.2$ in this model were used to conduct subgroup analyses. All analyses were run blindly per protocol in Stata SE 14.0 (Stata Corp, College Station, TX) with a two-sided $\mathrm{P} \leq 0.05$ and an open dataset as explained in Dermata et al, [2020].

\section{Results}

Forty three children, 22 girls and 21 boys, met the inclusion criteria (Table 2). The mean age of the children was $70.2 \pm 14.3$ months. They received 161 restorations, 82 regular and 79 nano filled RMGIC restorations (Table 3). The results are presented separately in tables $4 \mathrm{a}, 4 \mathrm{~b}$ and $4 \mathrm{cfor}$ the 12 -month, the 24-month and the 36-month evaluation respectively, and further notes are made about statistical significance in the text for each assessed parameter.

Regarding the anatomical form the difference between nano filled and regular RMGIC restorations was statistically significant at all time points in favour of nano filled RMGIC when focused only in the $A$ and B marks (statistical significance levels appear in Tables 4a, 4b, 4c for every parameter). Nevertheless, when the restorations were dichotomized as acceptable $(A+B)$ or unacceptable $(C+D)$ for anatomical form, there was no statistically significant difference between the two materials. For the parameter of marginal integrity, the difference between the two materials was statistically significant at all the time points between the A 
and $\mathrm{B}$ marks with more regular RMGIC restorations being rated as $\mathrm{A}$. When the restorations were cumulatively judged as acceptable or unacceptable, the difference was again not statistically significant (Table 5).

After taking into account clustering effects of multiple restorations within each patient, no statistically significant difference could be seen with regression analyses between the two materials for all-cause failure (i.e. failure of at least one USPHS criterion). Regarding potential confounders, no influence of patient sex, mouth side, molar type, or cavity type on all-cause failure was seen (Table 6). However, restored maxillary primary molars were significantly less likely to fail than restored mandibular primary molars $(\mathrm{HR}=0.28 ; 95 \%$ $\mathrm{Cl}=0.10$ to $0.79 ; \mathrm{p}=0.02$ ). Subgroup analyses according to jaw indicated that both materials exhibited similar hazards for all-cause failure for maxillary molars $(n=84$ teeth; $p=0.59)$; for mandibular molars the regular RMGIC was associated with significantly less all-cause failures than the nano filled RMGIC ( $n=77$ teeth; $\mathrm{HR}=0.36 ; 95 \% \mathrm{Cl}=0.13$ to $0.96 ; \mathrm{p}=0.04)$.

There were no statistically significant differences between the two materials regarding recurrent caries and surface texture at any time point. Therefore, the hypothesis set out in aims was not disproved.

\section{Discussion}

According to the manufacturer, the nano filled RMGIC has better physical properties in comparison to those of regular RMGICs. Besides the typical GIC fluoroaluminosilicate glass, it contains silane-treated silica nanofillers and agglomerates or clusters of nano-sized zirconia/silica that appear as a single unit, that results in a highly packed filler composition (69\%). In the present study there were statistical differences between the two materials regarding the anatomical form and marginal integrity in the acceptable range of ratings (A vs. B), meaning that there was indeed less occlusal wear but more mild marginal defects (e.g. marginal discolouration) with nano filled than with regular RMGIC. The latter finding was seen also in 1year class V nano-filled RMGIC restorations [Perdigão et al, 2012]. This however was not translated to any difference in marginal secondary caries in the present study, as equal number of restorations (two) in each material were detected as such at the 36-month evaluation. More importantly, when the restorations were dichotomized as acceptable or unacceptable, there was no statistically significant difference between the two materials. Further, the results of the present 3-year study showed no statistically significant difference 
in the overall performance (all-cause failure) of nano-filled and regular RMGIC in class II primary molar restorations. This finding is in accordance with the study of Abo-Hamar et al [2015], who compared the exact brands tested in our study for 2 years, albeit in class I restorations.

RMGICs are widely used for the restorations of primary molars for over two decades. The experimental clinical study of Donly et al [1999], reported that regular RMGIC showed less demineralisation than amalgam in the proximal box margins of class II primary molar restorations. The intraoral findings of Kotsanos et al [2001] was in accordance with that observation. By use of the same materials as in the present study, fluoride release from the nano filled material was less but followed the same slowly decreasing pattern as from the regular RMGIC for a test period of 15 days [Paschoal et al, 2011] and 30 days [Upadhyay et al, 2013]. We could not therefore postulate that the mild marginal defects (marginal discolouration) found more often with nano filled than with regular RMGIC restorations are related to differences in the fluoride release of the two materials.

The question if the two materials have any differences in bonding with enamel cannot be answered by the present study as it was not in its aims. Despite containing amounts of polymerisable monomer, RMGICs still undergo acid-base setting reaction, allowing the ion exchange and the typical for GICs adhesion to the tooth-structure [Tyas, 2003]. Nano filled RMGIC is reported to contain more resin than regular RMGIC materials, resulting in a lower acid-base reaction and Ketac Nano restorations had worse marginal adaptation than those with the regular RMGIC in the 1-year evaluation [Perdigão et al, 2012]. Maybe these findings constitute a tentative explanations for the somewhat reduced marginal integrity of nano filled $(68.2 \%$ rated $\mathrm{A})$ compared to the regular $\mathrm{RMGIC}$ restorations $(94.4 \%$ rated $\mathrm{A})$.

Regarding to possible study limitations, the present study did not follow a split mouth design. Taking into consideration, however, that the study took place in a private clinic practice, symmetrical caries pattern needs would have limited the number of patients eligible for the study, and might have led to selection of higher caries risk patients, thus introducing a possible selection bias. Further, the present study is the first one to study nano filled RMGIC class II restorations for 3 years. The long follow up however runs the risk of increased dropouts, especially when the study is carried out in a private clinic practice setting as opposed to a rather more strictly obeyed, reduced-fee, institutional clinic environment. The $44.3 \%$ for nano filled and 
the $34.2 \%$ for regular RMGIC restorations dropout rate after 3 years are suggestive of bias risk and constitute a limitation of the study.

\section{Conclusions}

Considering the limitations of the present study it can be concluded that nano filled RMGIC primary molar restorations showed less occlusal wear but more mild marginal defects than those with regular RMGIC, but these were of limited clinical significance. Overall, both materials performed favourably as class II primary molar restorative materials at the 3-year observation period. 


\section{References}

Abo-Hamar SE, El-Desouky SS, Abu Hamila NA. Two-year clinical performance in primary teeth of nanofilled versus conventional resin-modified glass-ionomer restorations. Quintessence Int. 2015 May;46(5):381-8. doi: 10.3290/j.qi.a33517.

Chadwick BL, Evans DJ. Restoration of class II cavities in primary molar teeth with conventional and resin modified glass ionomer cements: a systematic review of the literature.Eur Arch Paediatr Dent.2007;Mar;8(1):14-21.

de Paula AB, Fucio SB, Ambrosano GM, Alonso RC, Sardi JC, Puppin-Rontani RM. Biodegradation and abrasivewear of nanorestorativematerials. Oper Dent. 2011 Nov-Dec;36(6):670-7. doi: 10.2341/10-221L.

Dermata A, Papageorgiou SN, Fragkou S, Kotsanos N. Comparison of resinmodified glass ionomer cement and composite resin in class II primary molar restorations: a 2-year parallel randomised clinical trial. Eur Arch Paediatr Dent. 2018 Dec;19(6):393-401. doi: 10.1007/s40368-018-0371-7. Epub 2018 Oct 15.

Donly KJ, Segura A, Kanellis M, Erickson RL. Clinical performance and caries inhibition of resin-modified glass ionomer cement and amalgam restorations.J Am Dent Assoc. 1999 Oct;130(10):1459-66.

Eley BM. The future of dental amalgam: a review of the literature. Part 7: Possible alternative materials to amalgam for the restoration of posterior teeth. Br Dent J.1997 Jul 12;183(1):11-4.

Hickel R. Glass ionomers, cements, hybrid ionomers and compomers (long-term) clinical evaluation. Trans Acad Dent Mater. 1996;9:105-29.

Killian CM, Croll TP. Nano-ionomer tooth repair in pediatric dentistry. Pediatr Dent. 2010 NovDec;32(7):530-5.

Konde S, Raj S, Jaiswal D. Clinical evaluation of a new art material: Nanoparticulated resin-modified glass ionomer cement. J Int Soc Prev Community Dent. 2012 Jul;2(2):42-7. doi: 10.4103/2231-0762.109361.

Kotsanos N, Arizos S. Evaluation of a resin modified glass ionomer serving both as indirect pulp therapy and as restorative material for primary molars. Eur Arch Paediatr Dent. 2011;12(3):170-5.

Kotsanos N. An intraoral study of caries induced on enamel in contact with fluoride-releasing restorative materials. Caries Res.2001 May-Jun;35(3):200-4. 
Paschoal MA, Gurgel CV, Rios D Magal-haes AC, Buzalaf MA, Machado MA. Fluoride release profile of a nanofilled resin-modified glass ionomer cement. Braz Dent J. 2011;22(4):276-9.

PerdigãoJ, Dutra-Corrêa M, Saraceni SH, Ciaramicoli MT, Kiyan VH.Randomized clinical trial of two resinmodified glass ionomer materials: 1-year results.Oper Dent. 2012; 37(6): 591-601.

Tyas MJ. Milestones in adhesion: Glass-ionomer cements Journal of Adhesive Dentistry.2003;5(4):259-66.

Upadhyay S, Rao A, Shenoy R.Comparison of the amount of fluoride release from nanofilled resin modified glass ionomer, conventional and resin modified glass ionomer cements.J Dent (Tehran). 2013 Mar;10(2):134-40.

van Dijken JW, Kieri C, Carlén M. Longevity of extensive class II open-sandwich restorations with a resinmodified glass-ionomer cement. J Dent Res. 1999 Jul;78(7):1319-25. 
Table 1. van Dijken et al. [1999] modified USPHS clinical criteria after further modification for posterior teeth RMGIC restoration survival by removing colour parameters and separating interproximal contact from anatomical form.

\begin{tabular}{|c|c|c|c|}
\hline \multirow[t]{2}{*}{ Category } & \multicolumn{2}{|l|}{ Score } & \multirow[t]{2}{*}{ Criteria } \\
\hline & Acceptable & Unacceptable & \\
\hline \multirow{4}{*}{$\begin{array}{l}\text { Anatomical } \\
\text { form }\end{array}$} & A & & Restoration is continuous with existing tooth anatomy \\
\hline & B & & $\begin{array}{l}\text { Slightly under-contoured restoration; axial enamel } \\
\text { walls partly visible }\end{array}$ \\
\hline & & $\mathbf{C}$ & $\begin{array}{l}\text { Restoration heavily under-contoured; dentine exposed; } \\
\text { occlusion affected }\end{array}$ \\
\hline & & $\mathbf{D}$ & $\begin{array}{l}\text { Restoration is missing partially or totally; } \\
\text { replacement required }\end{array}$ \\
\hline \multirow{4}{*}{$\begin{array}{l}\text { Marginal } \\
\text { integrity }\end{array}$} & $\mathbf{A}$ & & Explorer does not catch; no crevice is visible \\
\hline & B & & Explorer catches but does not penetrate crevice \\
\hline & & $\mathbf{C}$ & Obvious crevice at margin; dentine may be exposed \\
\hline & & $\mathbf{D}$ & Restoration or tooth is fractured; restoration is mobile \\
\hline \multirow{4}{*}{$\begin{array}{l}\text { Interproximal } \\
\text { contact }\end{array}$} & $\mathbf{A}$ & & Proximal contact is present \\
\hline & B & & No resistance to floss but no open proximal space \\
\hline & & $\mathbf{C}$ & No proximal contact \\
\hline & D & & $\begin{array}{l}\text { Absence of an adjacent } \\
\text { proximal surface }\end{array}$ \\
\hline \multirow{2}{*}{$\begin{array}{l}\text { Recurrent } \\
\text { caries }\end{array}$} & $\mathbf{A}$ & & No caries at restoration margin \\
\hline & & $\mathbf{D}$ & Caries at restoration margin \\
\hline \multirow{4}{*}{$\begin{array}{l}\text { Surface } \\
\text { texture }\end{array}$} & $\mathbf{A}$ & & Smooth, similar to polished enamel \\
\hline & B & & Slightly rough or pitted \\
\hline & $\mathbf{C}$ & & Rough, cannot be refinished \\
\hline & & $\mathbf{D}$ & Coarse surface pitting, irregular grooves \\
\hline
\end{tabular}


Table 2. Descriptive characteristics of the study sample at baseline.

\begin{tabular}{|l|l|l|l|l|l|}
\hline & & & Ketac & Vitremer & $\mathbf{P}$ \\
\hline Patients & Sex & Female - n (\%) & $15(68 \%)$ & $7(33 \%)$ & $0.02^{\dagger}$ \\
\hline & & Male - n (\%) & $7(32 \%)$ & $14(67 \%)$ & \\
\hline & & & & & \\
\hline & Restorations & Median (IQR) & $3(2-5)$ & $4(3-4)$ & $0.69^{*}$ \\
\hline & & & & & \\
\hline Teeth & Jaw & Mandible - n (\%) & $34(43.0 \%)$ & $43(52.4 \%)$ & $0.31^{\S}$ \\
\hline & & Maxilla - n (\%) & $45(57.0 \%)$ & $39(47.6 \%)$ & \\
\hline & & & & & \\
\hline & Side & Right - n (\%) & $41(51.9 \%)$ & $32(39.0 \%)$ & $0.04 \S$ \\
\hline & & Left - n (\%) & $38(48.1 \%)$ & $50(61.0 \%)$ & \\
\hline & & & & & \\
\hline & Molar & First - n (\%) & $43(54.4 \%)$ & $46(56.1 \%)$ & $0.72 \S$ \\
\hline & & Second - n (\%) & $36(45.6 \%)$ & $36(43.9 \%)$ & \\
\hline & & & & & \\
\hline & Cavity & Mesial - n (\%) & $38(48.1 \%)$ & $32(39.0 \%)$ & $0.07 \S$ \\
\hline & & Distal - n (\%) & $41(51.9 \%)$ & $50(61.0 \%)$ & \\
\hline
\end{tabular}

$I Q R$, interquartile range.

† from chi-squared test

* from Mann-Whitney test

$\S$ from generalized linear modeling for the binomial family with robust for clustering standard errors 
Table 3. Teeth available for evaluation at each timepoint.

\begin{tabular}{|l|l|l|l|l|l|}
\hline & \multicolumn{2}{|c|}{ Ketac } & \multicolumn{2}{c|}{ Vitremer } & \\
\hline Months & Present & Drop-outs & Enter & Drop-outs & P \\
\hline 6 & $79(100.0 \%)$ & $0(0 \%)$ & $82(100.0 \%)$ & $0(0 \%)$ & - \\
\hline 12 & $78(98.7 \%)$ & $1(1.3 \%)$ & $81(98.8 \%)$ & $1(1.2 \%)$ & $1.00^{€}$ \\
\hline 18 & $77(97.5 \%)$ & $2(2.5 \%)$ & $76(92.7 \%)$ & $6(7.3 \%)$ & $0.28^{€}$ \\
\hline 24 & $74(93.7 \%)$ & $5(6.3 \%)$ & $67(81.7 \%)$ & $15(18.3 \%)$ & $0.02^{*}$ \\
\hline 30 & $47(59.5 \%)$ & $32(40.5 \%)$ & $62(75.6 \%)$ & $20(24.4 \%)$ & $0.03^{*}$ \\
\hline 36 & $44(55.7 \%)$ & $35(44.3 \%)$ & $54(65.9 \%)$ & $28(34.2 \%)$ & $0.19^{*}$ \\
\hline
\end{tabular}

EfromFisherexacttest

* from chi square test 
Table 4a. Results at 12 months for the nano filled (Ketac Nano) and the regular RMGIC

(Vitremer) restorations

\begin{tabular}{|c|c|c|c|c|c|c|c|c|}
\hline \multirow[b]{2}{*}{ Failure } & \multicolumn{4}{|c|}{ Separate categories } & \multicolumn{4}{|c|}{ Restoration status } \\
\hline & Score & KetacNano & Vitremer & $\mathbf{p}$ & Status & $\begin{array}{l}\text { KetacNan } \\
0\end{array}$ & Vitremer & $\mathbf{p}$ \\
\hline All-cause & & & & & Acceptable & $\begin{array}{l}67 \\
(85.9 \%)\end{array}$ & $74(91.4 \%)$ & $0.28^{*}$ \\
\hline & & & & & Failure & $\begin{array}{l}11 \\
(14.1 \%)\end{array}$ & $7(8.6 \%)$ & \\
\hline Anatomical form & A & 73 (93.6\%) & $43(53.1 \%)$ & $\begin{array}{l}<0.00 \\
1 €\end{array}$ & Acceptable & $\begin{array}{l}74 \\
(94.9 \%)\end{array}$ & 79 (97.5\%) & $0.44^{€}$ \\
\hline & $\mathrm{B}$ & $1(1.3 \%)$ & $36(44.4 \%)$ & & Failure & $4(5.1 \%)$ & $2(2.5 \%)$ & \\
\hline & C & $2(2.6 \%)$ & $1(1.2 \%)$ & & & & & \\
\hline & $\mathrm{D}$ & $2(2.6 \%)$ & $1(1.2 \%)$ & & & & & \\
\hline $\begin{array}{l}\text { Marginal } \\
\text { integrity }\end{array}$ & A & $56(72.7 \%)$ & $73(90.1 \%)$ & $\begin{array}{l}0.009 \\
€\end{array}$ & Acceptable & $\begin{array}{l}70 \\
(90.9 \%)\end{array}$ & $77(95.1 \%)$ & $0.36^{€}$ \\
\hline & $\mathrm{B}$ & $14(18.2 \%)$ & $4(4.9 \%)$ & & Failure & $7(9.1 \%)$ & $4(4.9 \%)$ & \\
\hline & C & $4(5.2 \%)$ & $4(4.9 \%)$ & & & & & \\
\hline & $\mathrm{D}$ & $3(3.9 \%)$ & $0(0 \%)$ & & & & & \\
\hline Caries & No & $73(94.8 \%)$ & 77 (95.1\%) & $1.00^{€}$ & Acceptable & $\begin{array}{l}73 \\
(94.8 \%)\end{array}$ & $77(95.1 \%)$ & $1.00^{€}$ \\
\hline & Yes & $4(5.2 \%)$ & $4(4.9 \%)$ & & Failure & $4(5.2 \%)$ & $4(4.9 \%)$ & \\
\hline Surface texture & A & $74(97.4 \%)$ & $76(93.8 \%)$ & $0.44^{€}$ & Acceptable & $\begin{array}{l}76 \\
(100.0 \%)\end{array}$ & $81(100.0 \%)$ & $\mathrm{NC}$ \\
\hline & $\mathrm{B}$ & \begin{tabular}{|l|}
$2(2.6 \%)$ \\
\end{tabular} & $5(6.2 \%)$ & & Failure & $0(0 \%)$ & $0(0 \%)$ & \\
\hline & $\mathrm{C}$ & $0(0 \%)$ & $0(0 \%)$ & & & & & \\
\hline & $\mathrm{D}$ & $0(0 \%)$ & $0(0 \%)$ & & & & & \\
\hline Contact point & A & $78(100.0 \%)$ & $81(100.0 \%)$ & $\mathrm{NC}$ & Acceptable & $\begin{array}{l}78 \\
(100.0 \%)\end{array}$ & $81(100.0 \%)$ & $\mathrm{NC}$ \\
\hline & $\mathrm{B}$ & $0(0 \%)$ & $0(0 \%)$ & & Failure & $0(0 \%)$ & $0(0 \%)$ & \\
\hline & $\mathrm{C}$ & $0(0 \%)$ & $0(0 \%)$ & & & & & \\
\hline & $\mathrm{D}$ & $0(0 \%)$ & $0(0 \%)$ & & & & & \\
\hline
\end{tabular}

NC, not calculable.

* by chi square test

$€$ by Fisher exact test 
Table 4b. Results at 24 months for the nano filled (Ketac Nano) and the regular RMGIC (Vitremer) restorations.

\begin{tabular}{|c|c|c|c|c|c|c|c|c|}
\hline \multirow[b]{2}{*}{ Failue } & \multicolumn{4}{|c|}{ Separate categories } & \multicolumn{4}{|c|}{ Restoration status } \\
\hline & $\begin{array}{l}\text { Scor } \\
\text { e }\end{array}$ & $\begin{array}{l}\text { Ketac } \\
\text { Nano }\end{array}$ & Vitremer & $\mathbf{p}$ & Status & Ketac Nano & Vitremer & $\mathbf{p}$ \\
\hline \multirow{2}{*}{ All-cause } & & & & & Acceptable & $63(85.1 \%)$ & $61(91.0 \%)$ & $0.28^{*}$ \\
\hline & & & & & Failure & $11(14.9 \%)$ & $6(9.0 \%)$ & \\
\hline \multirow[t]{4}{*}{ Anatomical form } & A & $68(91.9 \%)$ & $35(52.2 \%)$ & $\begin{array}{l}<0.001 \\
€\end{array}$ & Acceptable & $70(94.6 \%)$ & $65(97.0 \%)$ & $0.68^{€}$ \\
\hline & $\mathrm{B}$ & $2(2.7 \%)$ & $30(44.8 \%)$ & & Failure & $4(5.4 \%)$ & $2(3.0 \%)$ & \\
\hline & C & $3(4.1 \%)$ & $1(1.5 \%)$ & & & & & \\
\hline & $\mathrm{D}$ & $1(1.4 \%)$ & $1(1.5 \%)$ & & & & & \\
\hline \multirow[t]{4}{*}{ Marginal integrity } & A & $53(71.6 \%)$ & $62(92.5 \%)$ & $0.001^{€}$ & Acceptable & $67(90.5 \%)$ & $64(95.5 \%)$ & $0.33^{€}$ \\
\hline & $\mathrm{B}$ & $14(18.9 \%)$ & $2(3.0 \%)$ & & Failure & $7(9.5 \%)$ & $3(4.5 \%)$ & \\
\hline & C & $4(2.7 \%)$ & $3(4.5 \%)$ & & & & & \\
\hline & $\mathrm{D}$ & $5(6.8 \%)$ & $0(0 \%)$ & & & & & \\
\hline \multirow[t]{2}{*}{ Caries } & No & $70(94.6 \%)$ & $64(95.5 \%)$ & $1.00^{€}$ & Acceptable & $70(94.6 \%)$ & $64(95.5 \%)$ & $1.00^{€}$ \\
\hline & Yes & $4(5.4 \%)$ & $3(4.5 \%)$ & & Failure & $4(5.4 \%)$ & $3(4.5 \%)$ & \\
\hline \multirow[t]{4}{*}{ Surface texture } & A & $71(97.3 \%)$ & $64(95.5 \%)$ & $0.67^{€}$ & Acceptable & $73(100.0 \%)$ & $67(100.0 \%)$ & $\mathrm{NC}$ \\
\hline & B & $2(2.7 \%)$ & $3(4.5 \%)$ & & Failure & $0(0 \%)$ & $0(0 \%)$ & \\
\hline & $\mathrm{C}$ & $0(0 \%)$ & $0(0 \%)$ & & & & & \\
\hline & D & $0(0 \%)$ & $0(0 \%)$ & & & & & \\
\hline \multirow[t]{4}{*}{ Contact point } & A & $\begin{array}{l}74 \\
(100.0 \%)\end{array}$ & $\begin{array}{l}67 \\
(100.0 \%)\end{array}$ & $\mathrm{NC}$ & Acceptable & $74(100.0 \%)$ & $67(100.0 \%)$ & $\mathrm{NC}$ \\
\hline & $\mathrm{B}$ & $0(0 \%)$ & $0(0 \%)$ & & Failure & $0(0 \%)$ & $0(0 \%)$ & \\
\hline & C & $0(0 \%)$ & $0(0 \%)$ & & & & & \\
\hline & $\mathrm{D}$ & $0(0 \%)$ & $0(0 \%)$ & & & & & \\
\hline
\end{tabular}

NC, not calculable.

* from chi square test

$€$ from Fisher exact test 
Table 4c. Results at 36 months for the nano filled (Ketac Nano) and the regular RMGIC (Vitremer) restorations.

\begin{tabular}{|c|c|c|c|c|c|c|c|c|}
\hline & Separ & categories & & & Restoratior & status & & \\
\hline Failue & Score & Ketac Nano & Vitremer & $\mathbf{p}$ & Status & Ketac Nano & Vitremer & $\mathbf{p}$ \\
\hline All-cause & & & & & Acceptable & $35(79.6 \%)$ & $50(92.6 \%)$ & $0.08^{€}$ \\
\hline & & & & & Failure & $9(20.5 \%)$ & $4(7.4 \%)$ & \\
\hline & & & & & & & & \\
\hline Anatomical form & A & $39(88.6 \%)$ & $27(50.0 \%)$ & $\begin{array}{l}<0.001 \\
€\end{array}$ & Acceptable & $40(90.9 \%)$ & $52(96.3 \%)$ & $0.40^{\epsilon}$ \\
\hline & $B$ & $1(2.3 \%)$ & $25(46.3 \%)$ & & Failure & $4(9.1 \%)$ & $2(3.7 \%)$ & \\
\hline & C & $3(6.8 \%)$ & $1(1.9 \%)$ & & & & & \\
\hline & $\mathrm{D}$ & $1(2.3 \%)$ & $1(1.9 \%)$ & & & & & \\
\hline Marginal integrity & A & $30(68.2 \%)$ & $51(94.4 \%)$ & $0.001^{€}$ & Acceptable & $39(88.6 \%)$ & $53(98.2 \%)$ & $0.09^{€}$ \\
\hline & $\mathrm{B}$ & $9(20.5 \%)$ & $2(3.7 \%)$ & & Failure & $5(11.4 \%)$ & $1(1.9 \%)$ & \\
\hline & $\mathrm{C}$ & $1(2.3 \%)$ & $1(1.9 \%)$ & & & & & \\
\hline & $\mathrm{D}$ & $4(9.1 \%)$ & $0(0 \%)$ & & & & & \\
\hline Caries & No & $42(95.5 \%)$ & $52(96.3 \%)$ & $1.0)^{€}$ & Acceptable & $42(95.5 \%)$ & $52(96.3 \%)$ & $1.00^{\epsilon}$ \\
\hline & Yes & $2(4.6 \%)$ & $2(3.7 \%)$ & & Failure & $2(4.6 \%)$ & $2(3.7 \%)$ & \\
\hline Surface texture & A & $41(954 \%)$ & $52(963 \%)$ & $100 €$ & Accentable & $43(1000 \%)$ & & $\mathrm{NC}$ \\
\hline & & & & & & & $(100.0 \%)$ & \\
\hline & B & $2(4.7 \%)$ & $2(3.7 \%)$ & & Failure & $0(0 \%)$ & $0(0 \%)$ & \\
\hline & C & $0(0 \%)$ & $0(0 \%)$ & & & & & \\
\hline & $\mathrm{D}$ & $0(0 \%)$ & $0(0 \%)$ & & & & & \\
\hline & & & & & & & & \\
\hline Contact point & A & $39(95.1 \%)$ & $46(88.5 \%)$ & $0.01^{€}$ & Acceptable & $39(95.1 \%)$ & $\begin{array}{l}82 \\
(100.0 \%)\end{array}$ & $0.19^{€}$ \\
\hline & $\mathrm{B}$ & $0(0 \%)$ & $6(11.5 \%)$ & & Failure & $2(4.9 \%)$ & $0(0 \%)$ & \\
\hline & C & $2(4.9 \%)$ & $0(0 \%)$ & & & & & \\
\hline & $\mathrm{D}$ & $0(0 \%)$ & $0(0 \%)$ & & & & & \\
\hline
\end{tabular}

NC, not calculable.

* from chi square test

$€$ from Fisher exact test 
Table 5. Cox regression of failure differences according to material, using proportional odds.

\begin{tabular}{|l|l|l|l|}
\hline Failure & Material & HR (95\% CI) & $\mathbf{P}$ \\
\hline All-cause & Vitremer & $0.58(0.25-1.31)$ & 0.19 \\
\hline & Ketac Nano & Reference & \\
\hline & & & \\
\hline Anatomical form & Vitremer & $0.32(0.06-1.60)$ & 0.17 \\
\hline & Ketac Nano & Reference & \\
\hline & & & \\
\hline Marginal integrity & Vitremer & $0.55(0.17-1.78)$ & 0.32 \\
\hline & Ketac Nano & Reference & \\
\hline & & & \\
\hline Caries & & & \\
\hline & Vitremer & $0.96(0.20-4.64)$ & 0.96 \\
\hline & Ketac Nano & Reference & \\
\hline Surface texture & & & \\
\hline & Vitremer & No failure & - \\
\hline & Ketac Nano & Reference & \\
\hline Contact point & Vitremer & $<0.01$ & \\
\hline & Ketac Nano & Reference & \\
\hline
\end{tabular}

$\mathrm{HR}$, hazard ratio; $\mathrm{Cl}$, confidence interval. 
Table 6. Univariable Cox regression of all-cause failure / separate criterion failures used to identify confounding variables to add in the adjusted analyses of Table 4.

\begin{tabular}{|l|l|l|l|}
\hline & & All cause & \\
\hline Factor & Group & HR (95\% Cl) & P \\
\hline Sex & Male & $1.06(0.47-2.38)$ & 0.89 \\
\hline & Female & Reference & \\
\hline & & & \\
\hline Jaw & Maxilla & $0.28(0.10-0.79)$ & 0.02 \\
\hline & Mandible & Reference & \\
\hline Side & Right & $0.63(0.30-1.31)$ & 0.22 \\
\hline & Left & Reference & \\
\hline & & & \\
\hline Molar & Second & $0.75(0.31-1.85)$ & 0.54 \\
\hline & First & Reference & \\
\hline & & & \\
\hline Cavity & Disto-occlusal & $1.25(0.51-3.08)$ & 0.62 \\
\hline & $\begin{array}{l}\text { Mesio- } \\
\text { occlusal }\end{array}$ & Reference & \\
\hline
\end{tabular}

$\mathrm{HR}$, hazard ratio; $\mathrm{Cl}$, confidence interval.

\section{Subgroup analyses}

Effect of material on all-cause failure after taking into account jaw (maxilla vs mandible) into account: Maxilla

HR: 1.60; 95\% Cl: 0.29-8.74; P=0.59

Mandible

HR: 0.36; 95\% Cl: 0.13-0.96; P=0.04 